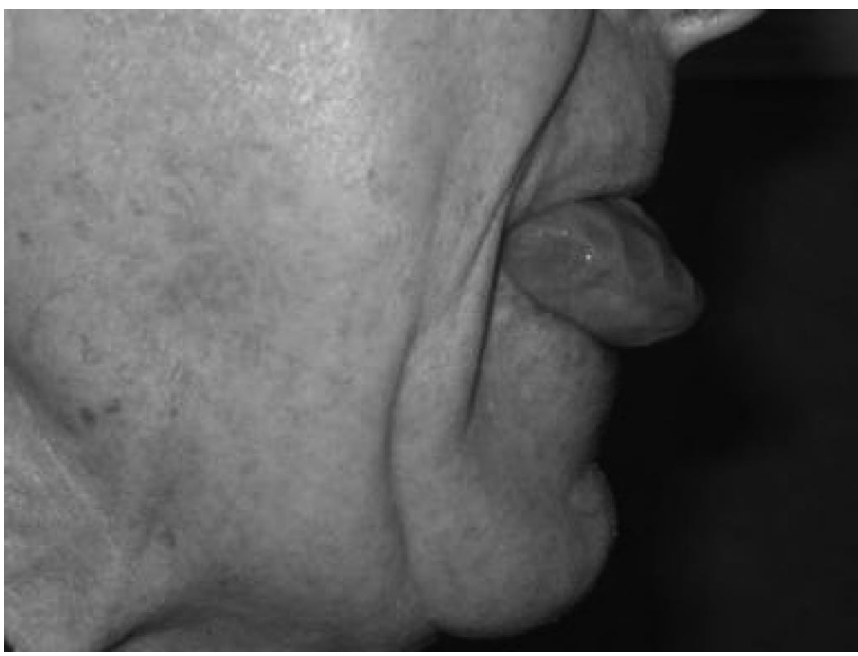

Figure 1. Macroglossia in profile.

\section{Dysarthria and dysphagia from light chain amyloidosis}

Khalid Tabbarah, MD; John Madden, MD, PhD; and Richard S. Bedlack, MD, PhD, Durham, NC

A 72-year-old man reported 6 months of painless, progressive dysarthria, dysphagia for solids, and a "crowded mouth." Review of systems was notable only for weight loss. Previous neurologists

\section{Disclosure: The authors report no conflicts of interest.}

Received March 3, 2005. Accepted in final form June 24, 2005.

Address correspondence and reprint requests to Dr. K. Tabbarah, Division of Neurology, Department of Medicine, Duke University Medical Center, PO Box 2905, Durham, NC 27710; e-mail: ktabbarah@nc.rr.com

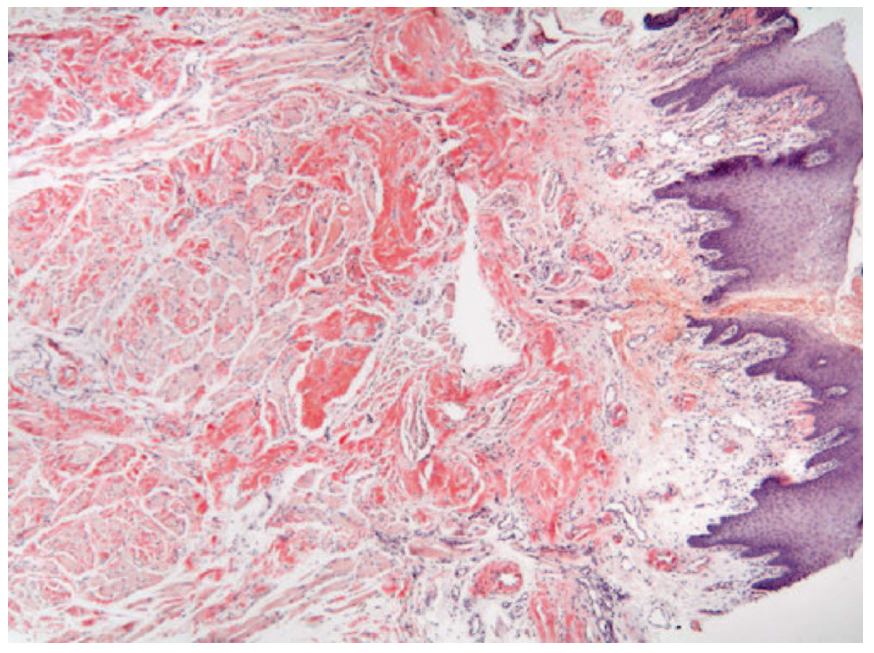

Figure 2. Histology of tongue biopsy. Low power $(\times 4)$, with Congo red staining. Mucosa at right. Perivascular and intramuscular amyloid deposits are seen diffusely.

diagnosed "bulbar myasthenia," but treatment failed to help. Exam showed nonfatigable lingual dysarthria, macroglossia (figure 1), and slow, weak lingual movements. Neck CT showed only diffuse tongue enlargement. Tongue biopsy revealed amyloid (figure 2). Further workup was consistent with light chain amyloidosis from multiple myeloma. ${ }^{1}$ Chemotherapy has not improved his neurologic symptoms to date.

Amyloidosis is the most common cause of adult macroglossia. Other causes include angioedema, lymphoma, hypothyroidism, and acromegaly. ${ }^{2}$

1. Jacobsen D. Amyloidosis, overview. E-medicine. Available at www. emedicine.com; accessed August 4, 2004.

2. Murthy P, Laing MR. Macroglossia. Br Med J 1994;309:386-387.

$\overline{\text { See also page } 1670}$ 


\title{
Neurology
}

\author{
Dysarthria and dysphagia from light chain amyloidosis \\ Khalid Tabbarah, John Madden and Richard S. Bedlack \\ Neurology 2005;65;1671 \\ DOI 10.1212/01.wnl.0000182295.32791.e5
}

This information is current as of November 21, 2005

\section{Updated Information \&} Services

References

Permissions \& Licensing

Reprints including high resolution figures, can be found at: http://n.neurology.org/content/65/10/1671.full

This article cites 5 articles, 0 of which you can access for free at: http://n.neurology.org/content/65/10/1671.full\#ref-list-1

Information about reproducing this article in parts (figures,tables) or in its entirety can be found online at:

http://www.neurology.org/about/about_the_journal\#permissions

Information about ordering reprints can be found online: http://n.neurology.org/subscribers/advertise

Neurology $®$ is the official journal of the American Academy of Neurology. Published continuously since 1951, it is now a weekly with 48 issues per year. Copyright . All rights reserved. Print ISSN: 0028-3878. Online ISSN: 1526-632X.

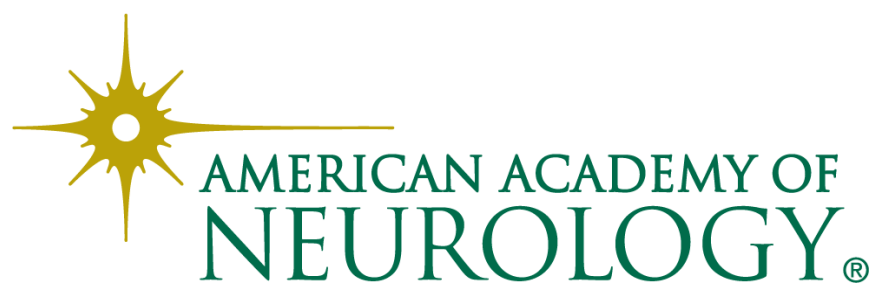

